\section{Therapeutic relationship: Is it still heart of nursing?}

Amir Mirhaghi, Simin Sharafi, Ali Bazzi, Farzaneh Hasanzadeh

Department of Medical-Surgical Nursing, School of Nursing and Midwifery, Mashhad University of Medical Sciences, Mashhad, Iran

\begin{abstract}
Relationship was introduced as an essential element of care since the beginning of theorizing in nursing. However therapeutic relationship has been conceptualized by different theorists, an integrated approach is not provided. This study aimed to perform a systematic review to explain the therapeutic relationship in the contemporary nursing practice. Electronic databases were searched from conception to October 2015 using keywords including therapeutic, relationship, communication, nurse, and patient. We used PRISMA guideline to report data. Original studies relevant to the therapeutic relationship were included. Exclusion criteria include abstracts that were irrelevant to the concept of study, grey literature and review and commentary articles. Disagreements between researchers were solved by consensus. Twenty studies were finally included into the review process. Data were organized into three categories including composition of therapeutic relationship, context of therapeutic relationship and confirmation of therapeutic relationship. The therapeutic relationship is composed of significant knowing and meaningful connecting with patients. Few studies confirmed applicability of therapeutic relationship in nursing practice. Therapeutic relationship ensures humanity to be preserved during nursing care and patients' hospital stay; it faces with strong barriers such as nursing shortage. The nursing shortage seriously threatens the heart of nursing. Therapeutic relationship needs to be investigated further in order to be supported by evidence-based nursing in order to confirm the applicability of relationshipbased caring theories.
\end{abstract}

\section{Introduction}

Relationship between nurse and patient is considered an essential element of care from ancient times ${ }^{1,2}$ and also the role of relationship has been recognized by nursing theorists since the beginning of theorizing in nursing. ${ }^{3}$ Relationship is an important tool for nurses. ${ }^{4}$ Interpersonal relationship between the patient and the nurse was introduced..$^{5}$ Florence Nightingale and Virginia Henderson have emphasized this point with phrases such as "for the patient" in their definitions of nursing, ${ }^{6}$ They believe the interpersonal, interactive, and constant relationship between the nurse and the client helps the patients improve their health. ${ }^{4}$ Peplau presented interpersonal relations theory and defined nursing as a therapeutic and effective interpersonal process that interacts cooperatively with other human processes to maintain their health. ${ }^{7}$ In this way, Travelbee presented human-to-human relationship model ${ }^{1}$ and defined nursing as an interpersonal process. ${ }^{3}$ However nursing theorists strongly emphasized in the value of relationship in nursing, current practice needs more updated evidence to use therapeutic relationship in nursing care.

The therapeutic relationship is the nurses' ability to consciously use their personality to get close to the patient to be able to perform the nursing interventions effectively, which indeed needs self-consciousness, self-awareness, and having a philosophy about life, death, and the overall human situation. ${ }^{8}$ Important features of this relationship involve mutual targeted experience, meeting the nursing needs of the individual or family, ${ }^{3}$ coordination and cooperation, ${ }^{9}$ being near the patient's bedside, ${ }^{10}$ honesty and empathy. ${ }^{11,12}$ While therapeutic relationship has been defined by several nursing scholars based on their viewpoints and personal experiences, we need to provide a definition of therapeutic relationship with rigorous research methodology.

However the importance of relationship in nursing has been addressed in the literature of twentieth-one century, the applicability of the therapeutic relationship in nursing needs in-depth exploration because most studies on therapeutic relationship have not been performed systematically especially in the second half of the twentieth-first century and it is not clear whether these theories and viewpoints could be applicable in current nursing practice. The aim of the study is to perform a systematic review to explain the therapeutic relationship in the contemporary nursing practice.

\section{Methods of research}

A systematic review has been performed to retrieve studies that were related to therapeutic relationship in nursing. We performed this study based on Preferred Reporting Items for Systematic Reviews and Meta-Analyses (PRISMA) guideline
Correspondence: Amir Mirhaghi, Department of Medical-Surgical Nursing, Faculty of Nursing and Midwifery, Postcode: 9137913199, Chahrrah-e-Doktorha, Mashhad, Razavi Khorasan, Iran.

Tel.: +98.51.38591511 - Fax: +98.51.38539775.

E-mail: mirhaghia@mums.ac.ir

Key words: Therapeutic; relationship; nurse; patient.

Conflict of interests: the authors have no conflict of interests.

Received for publication: 4 July 2016 Revision received: 12 October 2016. Accepted for publication: 9 January 2017.

This work is licensed under a Creative Commons Attribution NonCommercial 4.0 License (CC BY-NC 4.0).

(C) Copyright A. Mirhaghi et al., 2017

Licensee PAGEPress, Italy

Nursing Reports 2017; 7:6129

doi:10.4081/nursrep.2017.6129

(Figure 1). This approach provides wide span in the search whilst investigating a research aim including identify, select, and examine relevant studies, and to summarize findings. Key search terms including therapeutic, relationship, communication, nurse, and patient were searched either as combined or separately. Search strategy was ("therapeutics" [MeSH Terms] OR "therapeutics"[All Fields] OR "therapeutic"[All Fields]) AND "relationship"[All Fields] AND ("nurse-patient relations" $[\mathrm{MeSH}$ Terms] OR ("nurse-patient"[All Fields] AND "relations"[All Fields]) OR "nursepatient relations"[All Fields] OR ("nurse"[All Fields] AND "patient"[All Fields]) OR "nurse patient"[All Fields]). No additional filter was used. Search results were collected from conception to October 2015. Preliminary results were screened to identify those, which are irrelevant, and the remaining articles were examined more in depth in the second round. Summary tables were developed. Abstracts were reviewed by two researchers independently to retrieve original studies relevant to the therapeutic relationship focusing on explanation of the concept. Exclusion criteria include abstracts that were irrelevant to the concept of study, grey literature and review and commentary articles. Abstracts about nurse-nurse, doctor-nurse, doctor-patient relationship and nurse's communication about disease with patients were removed. We did not exclude non-English inquires because significant publications have been published in Spanish and French. 
Disagreements between researchers were solved by consensus. Full-texts of remaining studies were reviewed completely and relevant journals and reference lists were also hand-searched to find more relevant studies.

\section{Results}

Twenty studies were finally included into the review process (Table 1). Eight studies originated from Australia and Canada. Ten studies also originated from psychiatric nursing settings. Most studies related to therapeutic relationship were commentary prior to 2000 and also original studies were rare. Extracted data were organized into three categories including composition of therapeutic relationship, context of therapeutic relationship and confirmation of therapeutic relationship.

\section{Composition of therapeutic relationship}

Most qualitative studies have explained the meaning of therapeutic relationship in nursing. Therapeutic relationship is primarily composed of significant knowing and meaningful connectedness. Knowing the patients is the main element of therapeutic relationship. ${ }^{13}$ The therapeutic relationship cannot be occurred unless the nurses know the whole person including the personality and the effect of disease on person and everyday life $^{14}$ resulting in targeting essence. ${ }^{15}$ Another element of therapeutic relationship is connectedness. ${ }^{13}$ Knowing the patients is contributed to a strong mutual connection between nurse and patient that must be capable of reciprocal exchange. ${ }^{16}$ This alliance is solely related to patient $^{14}$ and the nurse fully devoted to "being in the moment". ${ }^{16}$ Relationship attributes were identified as protective, ${ }^{17}$ hopeful, ${ }^{18}$ friendly, ${ }^{19}$ positive, ${ }^{16}$ humanistic, ${ }^{20}$ trustful, ${ }^{21}$ safe and secure..$^{22}$

\section{Context of therapeutic relationship}

Some studies address the context of therapeutic relationship in relation to nursing practice as well as contextual factors affecting the relationship including nurserelated, patient-related and organizationrelated. ${ }^{23}$

Nurses must have significant learned experience originating from a meaningful life experience and they also must be competent in interpersonal skills. ${ }^{23}$ Besides, they must be capable of spending considerable time to know their patients, ${ }^{14}$ but the studies showed that therapeutic relationship does not occur systematically and as a result, patients could hardly distinguish nurses from other health care professionals. $^{24}$ It is expected in clinical practice that therapeutic relationship has been illustrated in the shadow. ${ }^{25}$ It is worth mentioning that therapeutic relationship suffers from restrictive institutional poli$\operatorname{cies}^{26}$ that limit the development of therapeutic relationship in clinical practice.

\section{Confirmation of therapeutic rela- tionship}

Some studies examined the therapeutic relationship theories, so they tested Peplau's theory of interpersonal relations or the Relationship-based care model (RBC). While other studies defined outcome of therapeutic relationship as either "activating the power of the client" or "get to the solution". ${ }^{14,16}$ The explanatory power of theory was considerably depended on both nurse and client variables. ${ }^{27}$ Studies indicated that the extent of positive change such as alleviating anxiety is difficult to measure or relate to the development of therapeutic relationship. ${ }^{23,27}$ The RBC model showed a positive correlation with length of stay and a nega- tive correlation with readmission rates. The RBC model did not indicate a significant increase in overall satisfaction with nursing. ${ }^{28}$

\section{Discussion and Conclusions}

Investment of the self in the nursepatient relationship is pivotal to establish therapeutic relationship including knowing and connecting with patients. ${ }^{29}$ Therapeutic relationship is also associated with "self", so it has been overemphasized by nursing theorists. ${ }^{30-36}$ However the concept of "self" depends on personal reflection and social interaction, it is generally defined as the conscious of individual. ${ }^{33}$ Intelligent and meaningful lived experience is necessary to expand conscious of individual significantly. ${ }^{13}$ Therapeutic use of "self" occurs when nurses consciously use their own character and knowledge to make a difference in the patient outcomes ${ }^{34-37}$ or "activating the power of the client" or "get to the

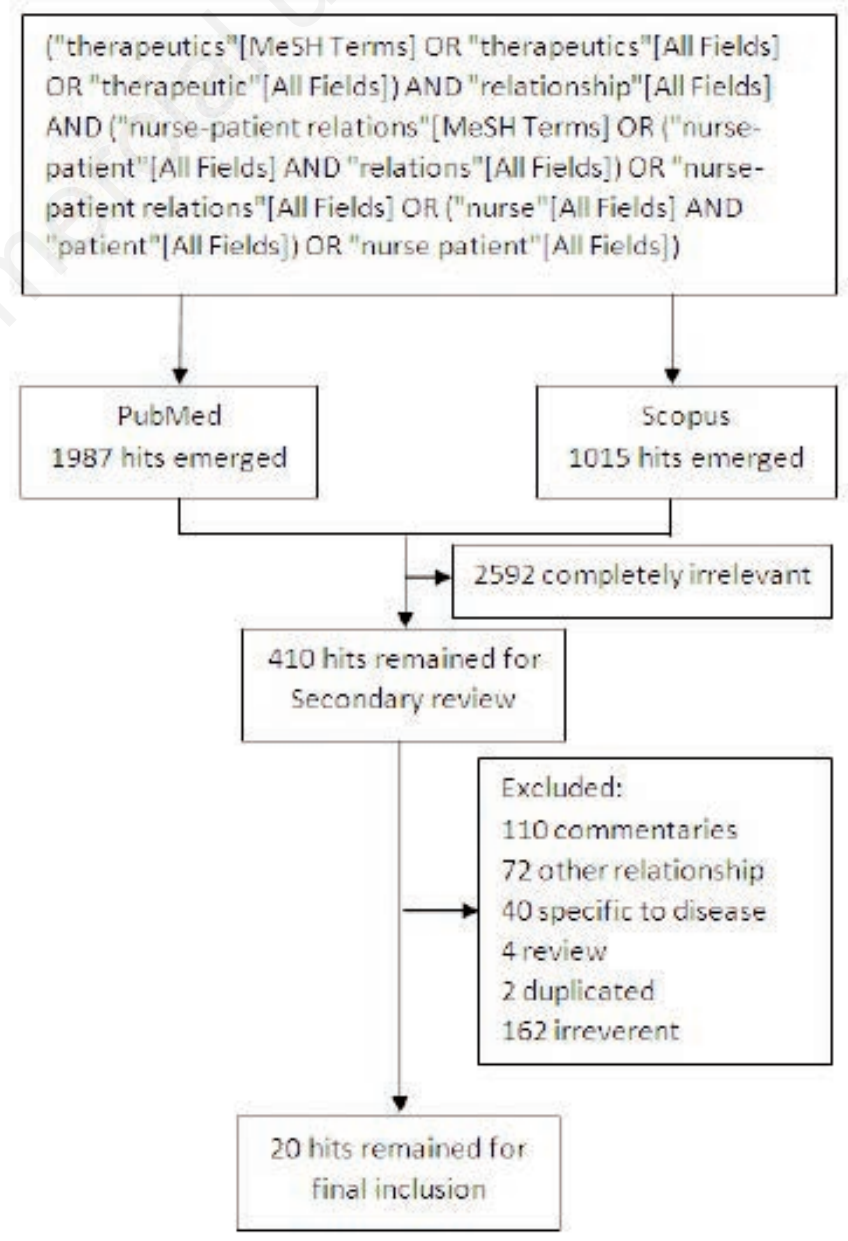

Figure 1. Literature search and retrieval flow diagram. 

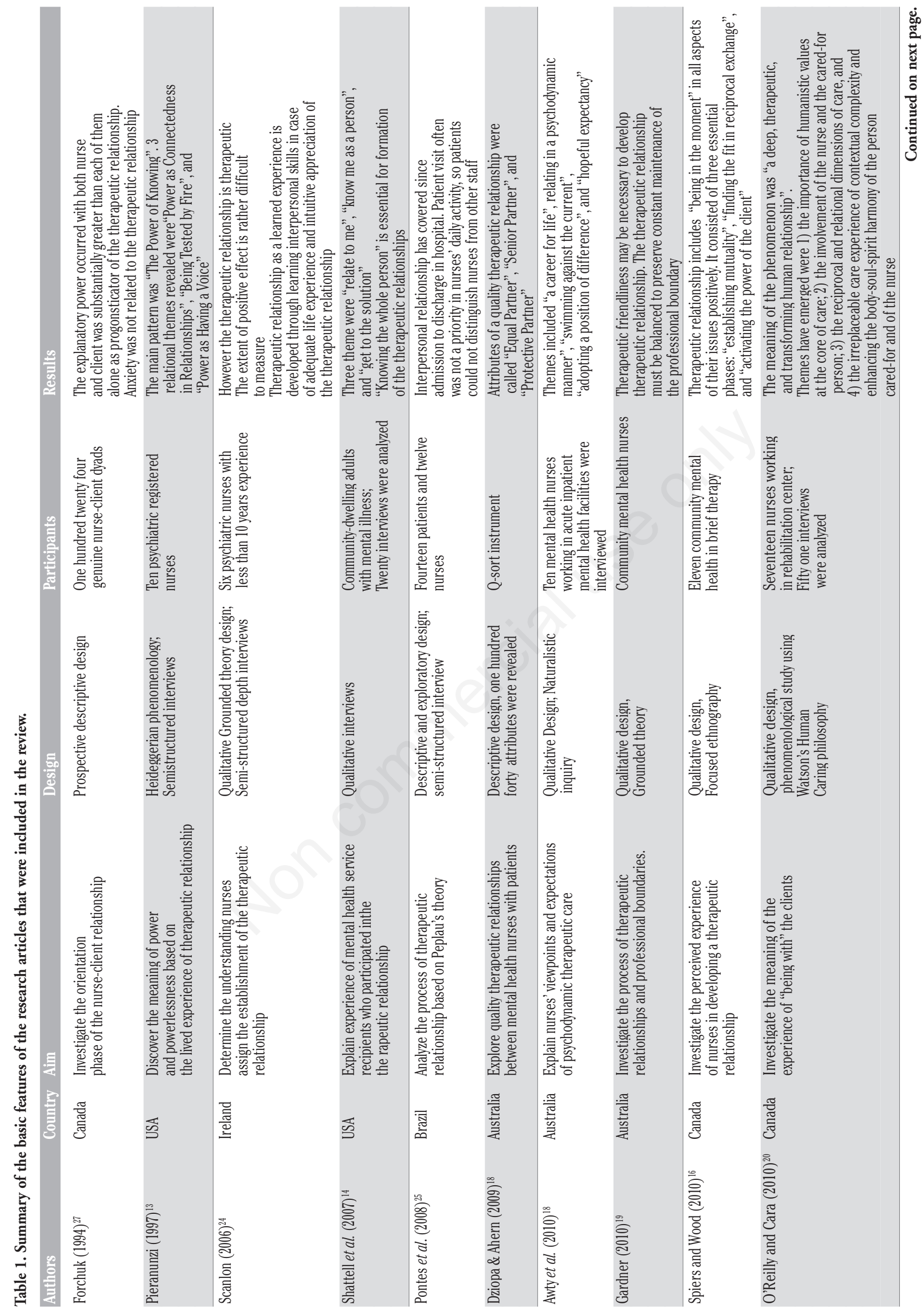

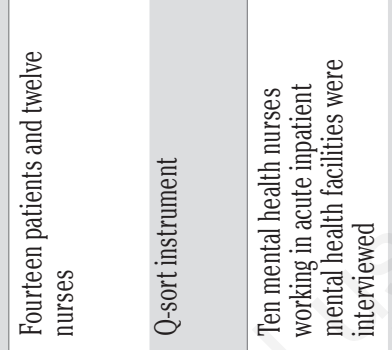

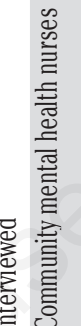
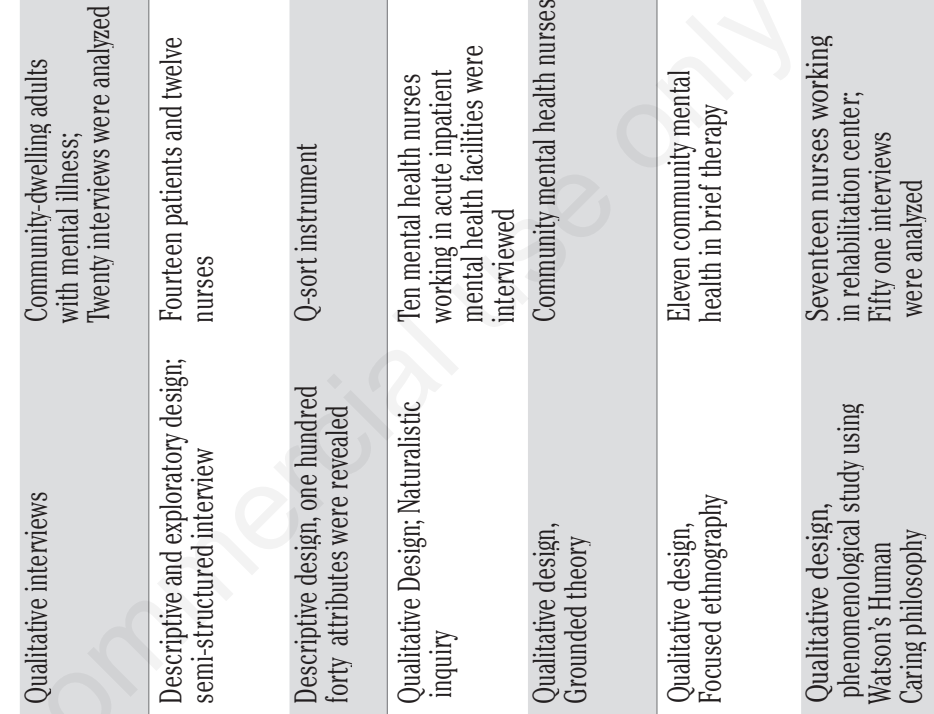


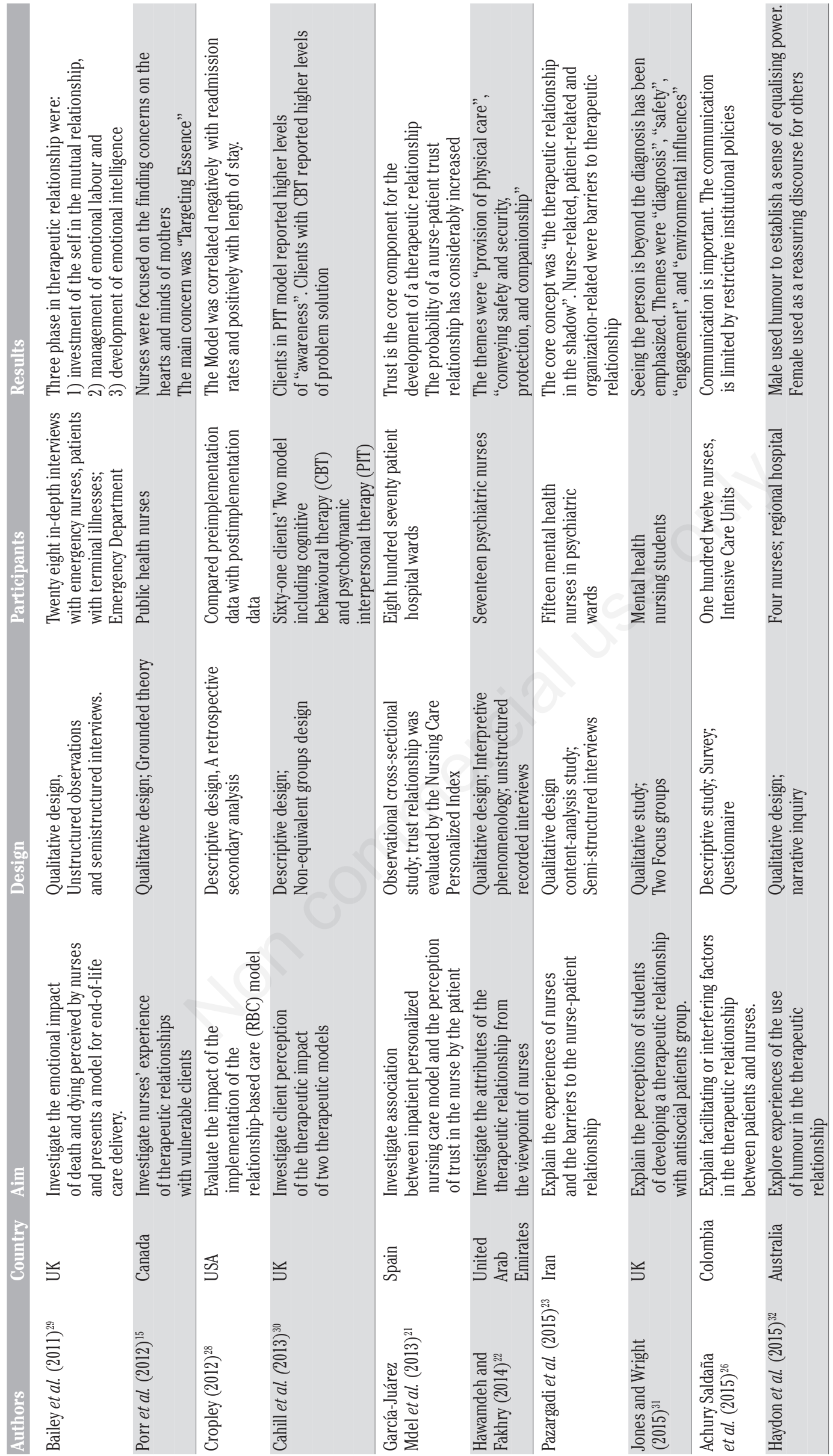


solution". ${ }^{14,16}$ Although Ersser has questioned whether this process happens deliberately, ${ }^{38}$ most studies have argued that this process occur with conscious and deliberate use of human traits or personality to help the patients. ${ }^{33}$ In other words, therapeutic use of "self" involves the use of personality dimensions, life skills, and knowledge that a nurse could invest for establishing a relationship with the patient ${ }^{39}$ to develop the basis for caring interventions as well as understanding her or his needs. ${ }^{6}$ It has also been concluded that this type of interaction in nursing can vary from a natural tendency to a complex social skill. ${ }^{40}$

In detail, knowledge about the own patient, personal and interpersonal relations, evolutionary theory, cultural diversity, health and disease, the impact of health policies on patient care and health system has been defined essential as well as capabilities such as having awareness or knowledge about self, reciprocity, respect, honesty, empathy, and realization of the limitations of the nursing role. Contextual factors such as beliefs, values and attitudes, culture and religion, social status, gender, level of maturity or age and body language may play role in therapeutic relationshi. ${ }^{3,23,24,41,42}$ Self-awareness is considered the most central prerequisite for nurses to engage in therapeutic relationship. ${ }^{40}$ Self-awareness means that the nurses know how to respond to different situations, identify values, his attitude towards the people, and how they respond to their human needs. ${ }^{39}$ Muetzel also said that the ability of a nurse to participate in a therapeutic relationship depends on the human, personal, and professional evolution. ${ }^{9,33}$ It is obvious that therapeutic relationship guarantees humanity to be preserved during nursing care and patients' hospital stay because it respect for patients' dignity.

The therapeutic relationship of the nurse and patient has borders that separate them from the non-therapeutic relationship. Examples of therapeutic relationship includes the use of silence, acceptance, understanding, availability, permit the patient to speak, encourage the patient to talk and openness, time sharing, observing, encouraging conversation, comparing, reexpressing, reflecting, focusing, analyzing the issue, transparency, facing the reality, expressing doubts, expressing perceptions and feelings, achieving shared language, and evaluating the patient. In contrast, a non-therapeutic relationship, is faced with instances like false trusting, accepting or rejecting comments, withdrawal, agree or disagree, advice, curiosity, defending, holding up, scaring, showing disrespect, cliché and prejudiced ideas, denial, talking with- out reason, confronting, and discussing an irrelevant issue. ${ }^{6}$

Establishing relationship especially therapeutic relationship needs time. Enough time should be given to the relationship process between nurse and patient. Several reports and studies showed that the vast majority of nurses are too busy to talk to patients because they are over-worked. Westbrook et al. (2011) indicated that time in professional relationship is around 37\% of nurses' time. It's worth mentioning that almost $25 \%$ of this figure belongs to direct care such as bathing, applying dressings and ..., so it may be concluded that only a few hours may remain for therapeutic relationship. ${ }^{43}$ Disproportion between the nurses' working time with the time needed for therapeutic relationship causes the therapeutic relationship not to be formed and so it causes that nurses do not priorize the visit to patients among their routine activities. ${ }^{25,44}$ In this regard, studies have also shown that noncompliance with nurse-to-patient staffing ratios brings about adverse effects on the health condition of patients. ${ }^{45}$ Researchers have also shown that shorttime employment is an obstacle to therapeutic relationship that is accompanied by a decrease in nurses' satisfaction and separation in providing care. ${ }^{46}$ Another issue that may affect therapeutic relationship is burnout. Burnout is not uncommon in nursing and it is an important reason for job quitting among nurses. Studies also showed burnout affects nurse-patient relationship adversely as seen by low patient satisfaction. ${ }^{47}$

Therapeutic relationship may face internal barriers apart from institutional or professional ones. In nurses' communications with patients, nurses have more power, because they cause the patient to be placed in a state of vulnerability with more capabilities and stronger interpersonal abilities. ${ }^{17}$ Thus, it is very likely that the patient falls in a deep relationship with the nurse or vice versa that nurse needs to consider through self-awareness and familiarity with warning signs. ${ }^{48}$ This complex relationship needs special emotional involvement; thus psychological rehabilitation programs are needed for nurses to prevent their exhaustion that can impose cost to the health systems. ${ }^{3}$ In other hand, few relationship-based care models have been developed and confirmed. ${ }^{28}$ It may implies that current health care systems impose situations that only welcome expeditious caring model. Salyer (1995) clearly showed nurses on units with more rapid turnover perceived a decline in nurse-patient relationship as well as familynurse relationship. ${ }^{49}$

The therapeutic relationship is com- posed of significant knowing and meaningful connecting with patients, so it needs that nurses have essential knowledge and capabilities to form therapeutic self. However therapeutic relationship ensures humanity to be preserved during nursing care and patients' hospital stay, it faces with strong barriers such as nursing shortage. It's worth mentioning that the nursing shortage degenerates the essence of nursing and its effect is beyond lack of resources, so nurse must be aware of the threat related to nursing shortage. The therapeutic relationship also needs to be investigated further to be supported by evidence-based nursing in order to confirm the applicability of relationship-based caring theories.

\section{References}

1. Mirhaghi A, Mazlom R. Ethical themes in nursing driven from Shahnameh. Iranian J Nurs Res 2013;8:1-8.

2. Mirhaghi A, Mazloom S, Kooshiar H, Mohammadi G. Professional ethics and patient rights in care and cure: Viewpoint of Hakim Ferdowsi. J Neyshabur Univ Med Sci 2014;2:62-70 [In Persian].

3. Meleis AI. Theoretical nursing: development and progress. London: Lippincott Williams \& Wilkins; 2011.

4. Bischko D. The art of nursing: the client-nurse relationship as a therapeutic tool. Nurs Case Manag 1998;3:14850.

5. Moyle W. Nurse-patient relationship: A dichotomy of expectations. Int J Mental Health Nurs 2003;12:103-9.

6. Masters K. Role development in professional nursing practice. Jones and Bartlett; 2005.

7. Peplau H. Interpersonal Relations in Nursing. New York: Putnam; 1952.

8. Epstein R, Borrell F, Caterina M. Communication and mental health in primary care. Oxford: Oxford University Press; 2000.

9. Muetzel P. Therapeutic nursing, in primary nursing: nursing in the Burford and Oxford Nursing Development Units. Croom Helm: Beckenham; 1988.

10. Savage J. Nursing intimacy: an ethnographic approach to nurse-patient interaction. London: Scutari Press; 1995.

11. Olsen D. Empathy as an ethical and philosophical basis for nursing. Adv Nurs Sci 1991;14:62-75.

12. Reynolds W. The measurement and development of empathy in nursing. Aldershot: Ashgate Publishing; 2000.

13. Pieranunzi V. The lived experience of power and powerlessness in psychiatric 
nursing: a Heideggerian hermeneutical analysis. Arch Psychiatr Nurs 1997;11:155-62.

14. Shattell M, Starr S, Thomas S. 'Take my hand, help me out': mental health service recipients' experience of the therapeutic relationship. Int $\mathrm{J}$ Ment Health Nurs 2007;16:274-84.

15. Porr C, Drummond J, Olson K. Establishing therapeutic relationships with vulnerable and potentially stigmatized clients. Qual Health Res 2012;22:384-96.

16. Spiers J, Wood A. Building a therapeutic alliance in brief therapy: the experience of community mental health nurses. Arch Psychiatr Nurs 2010;24:37386.

17. Dziopa F, Ahern K. Three different ways mental health nurses develop quality therapeutic relationships. Issues Ment Health Nurs 2009 30:14-22.

18. Awty P, Welch A, Kuhn L. A naturalistic inquiry of registered nurses' perspectives and expectations of psychodynamic therapeutic care in acute psychiatric inpatient facilities. Arch Psychiatr Nurs 2010;24:104-13.

19. Gardner A. Therapeutic friendliness and the development of therapeutic leverage by mental health nurses in community rehabilitation settings. Contemp Nurse 2010;34:140-8.

20. O'Reilly L, Cara C. ["Being with" the person cared for in a rehabilitation context: a profound, therapeutic and transformative human relationship]. Rech Soins Infirm 2010;103:46-66. [Article in French].

21. García-Juárez Mdel R, López-Alonso S, Moreno-Verdugo A, et al. [Personalized nursing care in hospital and its effects on the patient-nurse trust relationship]. Enferm Clin 2013;23:243-51. [Article in Spanish].

22. Hawamdeh S, Fakhry R. Therapeutic relationships from the psychiatric nurses' perspectives: an interpretative phenomenological study. Perspect Psychiatr Care 2014 50:178-85.

23. Pazargadi M, Fereidooni Moghadam M, et al. The therapeutic relationship in the shadow: nurses' experiences of barriers to the nurse-patient relationship in the psychiatric ward. Issues Ment Health Nurs 2015;36:551-7.

24. Scanlon A. Psychiatric nurses' perceptions of the constituents of the therapeu- tic relationship: a grounded theory study. J Psychiatr Ment Health Nurs 2006;13:319-29.

25. Pontes A, Arruda Leitão I, Ramos I. [Therapeutic communication in Nursing: essential instrument of care]. Rev Bras Enferm 2008;61:312-8. [Article in Portuguese].

26. Achury Saldaña D, Pinilla Alarcón M, Alvarado Romero H. Aspects that facilitate or interfere in the communication process between nursing professionals and patients in critical state. Invest Educ Enferm 2015;33:102-11.

27. Forchuk C. The orientation phase of the nurse-client relationship: testing Peplau's theory. J Adv Nurs 1994;20:532-7.

28. Cropley S. The relationship-based care model: evaluation of the impact on patient satisfaction, length of stay, and readmission rates. J Nurs Adm 2012;42:333-9.

29. Bailey C, Murphy R, Porock D. Professional tears: developing emotional intelligence around death and dying in emergency work. J Clin Nurs 2011;20:3364-72.

30. Cahill J, Paley G, Hardy G. What do patients find helpful in psychotherapy? Implications for the therapeutic relationship in mental health nursing. J Psychiatr Ment Health Nurs 2013;20:782-91.

31. Jones E, Wright K. “They're really PD today": an exploration of mental health nursing students' perceptions of developing a therapeutic relationship with patients with a diagnosis of antisocial personality disorder. Int J Offender Ther Comp Criminol 2015:pii: $0306624 X 15594838$.

32. Haydon G, van der Reit P, Browne G. A narrative inquiry: Humour and gender differences in the therapeutic relationship between nurses and their patients. Contemp Nurse. 2015;14:1-13.

33. Freshwater D. Therapeutic nursing: improving patient care through selfawareness and reflection. SAGE; 2002.

34. Travelbee J. Interpersonal Aspects of Nursing. 2nd, editor. Philadelphia: F.A. Davis; 1971.

35. Hall L. The Loeb Center for Nursing and Rehabilitation. Int $\mathrm{J}$ Nurs Stud 1969;6:81-95.

36. Basavanthappa BT. Nursing theories. Jaypee Brothers; 2007.
37. George JB. Nursing theories: the base for professional nursing practice. Pearson Education; 2011.

38. Ersser SJ. Nursing as therapeutic activity: an ethnography. Aldershot: Avebury; 1997.

39. Elder R, Evans K, Nizette D. Psychiatric and mental health nursing. New York: Mosby; 2009.

40. McMahon R, Pearson A. Nursing as therapy: Stanley Thornes; 1998.

41. Orlando IJ. The dynamic nurse-patient relationship: function, process and principles. New York: Putnam; 1961.

42. Sandhu S, Arcidiacono E, Aguglia E, Priebe S. Reciprocity in therapeutic relationships: a conceptual review. Int J Ment Health Nurs 2015 [Epub ahead of print].

43. Westbrook JI, Duffield C, Li L, Creswick NJ. How much time do nurses have for patients? A longitudinal study quantifying hospital nurses' patterns of task time distribution and interactions with health professionals. BMC Health Serv Res 2011;11:319.

44. Cameron D, Kapur R, Campbell P. Releasing the therapeutic potential of the psychiatric nurse: a human relations perspective of the nurse-patient relationship. J Psychiatr Ment Health Nurs 2005;12:64-74.

45. Dimick JB, Swoboda SM, Pronovost PJ, Lipsett PA. Effect of nurse-topatient ratio in the intensive care unit on pulmonary complications and resource use after hepatectomy. Am J Crit Care 2001;10:376-82.

46. Baumann A, O'Brien-Pallas L, Armstrong-Stassen $\mathrm{M}$, et al. Commitment and care: The benefits of a healthy workplace for nurses, their patients and the system. A policy synthesis prepared for the Canadian Health Services Research Foundation and the Change Foundation. Ottawa: Canadian Health Services Research Foundation and the Change Foundation; 2001.

47. Vahey DC, Aiken LH, Sloane DM, et al. Nurse burnout and patient satisfaction. Med Care 2004;42:II57-66.

48. College of Nurses of Ontario. Practice standard: therapeutic nurse-client relationship; 2006.

49. Salyer J. Environmental turbulence. Impact on nurse performance. J Nurs Admin 1995;24:12-20. 